\title{
Embedding and Sustaining Equitable Practices in Teachers' Everyday Work: A Framework for Critical Action
}

\author{
ANN E. LOPEZ \\ Ontario Institute for Studies in Education \\ University of Toronto
}

\begin{abstract}
Diverse student populations are now one of the distinctive features of schools in North America. This changing demographic reality in schools places equity education that includes the lived experiences of diverse students at the centre of the teaching and learning process. However, research continues to show that despite the efforts and good work of teachers, huge gaps persist in the educational achievement and outcomes of Aboriginal students, students of colour, and poor children. Based on research conducted with teachers in Southern Ontario, Canada, grounded in critical pedagogy and culturally relevant teaching, this article examines the complexities of equity education and ways to better serve the needs of diverse students. Drawing from the author's experiences as a classroom teacher, administrator, and teacher educator, the article posits a framework for critical action on ways that teachers can embed equitable practices in their teaching.
\end{abstract}

\section{Introduction}

Diverse student populations are now one of the distinctive features of schools in North America. Canada's population has become more diverse and so has the student population, particularly in urban areas (Lopez, 2011a). Dealing with diversity is one of the fundamental challenges of twenty-first-century education (Darling-Hammond, 2011). This demographic shift has precipitated calls for schools to become more effective in meeting the needs of a more culturally, racially, and linguistically diverse school population, as well as confront gender, racial and economic disparity, and discrimination (Harper, 1997). There is an urgent need for schools and faculties of education to adequately prepare teachers for the racial and ethnocultural diversity that exists in Canadian and other Western societies in general (Dlamini, 2002). No matter what a teacher's social location might be in terms of class, ethnicity, race, and other forms of social identity, that teacher is most likely interacting on a daily basis with students whose backgrounds and experiences are different from his or her own (Dei, 1996). Hollins and Guzman (2005) found that many teachers who are assigned to teach diverse students in urban schools do 
not have the confidence in their ability to work well with diverse students and interact with parents from diverse backgrounds, and they feel inadequately prepared to teach students from culturally and linguistically diverse backgrounds. In Canada, the continued predominance of teachers who are mainly white, female, and middle class has not kept pace with the extraordinary growth in the number of students of colour (Ryan, Pollock, \& Antonelli, 2009). This makes the focus on equity and social justice education more crucial. I use equity and social justice interchangeably in this article from a critical lens that challenges, confronts, and disrupts structural inequalities, based on class, race, gender, and other social and human differences (Nieto \& Bode, 2008).

The lack of progress by many students from diverse backgrounds, and the persistence of the achievement gap have increased the need for more culturally responsive and equitable teaching. The 2006 Student Census in Ontario shows unacceptable drop out rates for racialized groups in the school system. For some groups this is as high as $40 \%$. In an increasingly diverse Ontario, educators have a responsibility to ensure that "all of our students are engaged, included, and respected, and that they see themselves reflected in their learning environment" (Ontario's Equity and Inclusive Education Strategy, 2009, p. 5). Despite the good work of many dedicated and talented teachers, there is a crisis of inequality in public schools that denies poor children and children of colour a high quality education (Zeichner, 2009).

One way of improving the education of diverse students is to make culturally relevant teaching and other equity approaches embedded in the curriculum and pedagogy. It is important that teachers move beyond a superficial, additive "feel-good" approach to equity education, in order to address the diversity that is present in our schools today (Nieto \& Bode, 2008). This article examines critical ways in which teachers can embed equity and culturally relevant teaching in their everyday practices. These strategies are based on research conducted with both new and experienced teachers in secondary schools. I also draw on my own experiences as a secondary classroom teacher, school administrator, and teacher educator. Fundamental to a critical approach is the acknowledgement that schooling is politically mediated and that no knowledge is neutral (Giroux, 1981). This approach is grounded in critical pedagogy (Freire, 1970; Giroux, 1997; McLaren, 1998) and culturally relevant teaching that challenge issues of power and seek to develop cultural competence, academic excellence and socio-political consciousness in students (Gay, 2000; Ladson-Billings, 1995a; 1995b). Critical pedagogy and 
culturally relevant teaching provide teachers with a framework to question current norms and engage in meaningful praxis. Critical elements in teaching allow teachers to critique the role of power in schooling and develop strategies that empower them to transform how they teach. Lee (2009) argued that equity education in the Canadian context, often has come to mean a superficial response to diversity and equity such as dances, dress, dialect, and food without looking at power relations, and calls for a more critical approach to equity education. According to Solomon \& Levine-Rasky (2003), educators have not embraced equity and diversity education, and implementation has been piecemeal and superficial. In their research conducted with elementary and secondary teachers from five school boards across Canada on their view of equity and diversity they found that:

Responses are contingent upon establishing a close fit with a personal interpretive framework and its associated values and investments. These positions inform...the sense an educator makes of difference and educational inequality as it impacts upon the lives of marginalized groups. They also inform how an educator implements equity and diversity education and the degree to which it will be accommodated or resisted. (Solomon \& Levine-Rasky, 2003, p.17)

As teachers embark on a journey of equity education, it is important that taken-for-granted practices such as the dominance of Eurocentric knowledge, essentializing of the 'other,' punishing racialized students more than others (Noguera, 2008), and other forms of exclusion and marginalization, be examined, disrupted, and unlearned in the process of teaching and learning.

\section{Critical Pedagogy and Culturally Relevant Teaching}

Critical pedagogy (Freire, 1970; Hooks, 1994; McLaren, 1998) provides a theoretical framework that disrupts current norms and offers new methodologies of praxis. Critical pedagogy offers a theoretical framework through which teachers question the assumptions they hold about the teaching self, students and schooling, examine their teaching contexts, assess their pedagogical practices, and make equity permanent elements in their teaching. It gives teachers a way of deconstructing their resistance to critical teaching practices, by opening avenues to 
examine ideologies and assumptions that they have of schooling and students. For example, some teachers continue to hold the view that they "do not see race," they "see only students." de Freitas and McAuley (2008) suggested that the well-intended habit of acting 'colour-blind' allows for certain beliefs about difference to go unquestioned, and for some it is a strategy to avoid examining the political and historical contexts of schooling. Critical pedagogy interrogates traditional methods of teaching, and establishes a paradigm that is based on creativity and contextuality, allowing students to have the best chances to perform at their maximum capabilities (Gay, 2000). This transformational praxis also embodies notions of culturally relevant teaching (Gay, 2000; Ladson- Billings, 1995). Culturally relevant teaching is a pedagogy that recognizes the diverse cultural characteristics of students from different cultural backgrounds, and adjusts teaching methods to account for this diversity (Gay, 2010). Culturally relevant pedagogy has emerged as an effective way of centering the cultures, languages and experiences that diverse students bring to classrooms, so as to increase their engagement and academic achievement (Irvine \& Armento, 2001; Villegas \& Lucas, 2002). The purpose of critical pedagogy is to engage learners in the act of what Freire calls conscientizacao, which has been defined as "learning to perceive social, political, and economic contradictions, and to take action against the oppressive elements of reality" (Freire, 1970/1995, p. 17). Both critical pedagogy and culturally relevant teaching, challenge teachers to examine ways that current schooling practices do not serve the needs of diverse students. Culturally relevant teachers aim to develop skills that will enable them to effectively engage all students in diverse classrooms. Culturally relevant pedagogy builds on the understanding of "how people are expected to go about learning may differ across cultures, and in order to maximize learning opportunities, teachers must gain knowledge of the cultures represented in their classrooms, then translate this knowledge into instructional practice" (Villegas, 1991, p. 13). Like critical pedagogy, culturally relevant pedagogy is a "pedagogy of opposition...committed to collective, not merely individual empowerment" (Ladson-Billings, 1995a, p. 160). Teachers who are unaware of cultural influences on learning, as well as the structure and substance of inequality, will find it difficult to understand students whose experience do not resemble their own (Darling-Hammond, 2011).

Equity and social justice education grounded in critical praxis and pedagogy, challenge us to ask: How can teachers be supported in developing equity pedagogies embedded in their daily practices that confront injustices and current norms? I combine critical pedagogy and 
culturally relevant teaching in my own practice as a teacher educator, as both allow me to critically examine schooling practices and the impact on diverse and racialized students, work towards teacher empowerment and transformation, and theorize ways that teachers can actively build on their ideological commitments to equity.

I agree with Dlamini (2002) who asserts that practical classroom applications of antiracism education and critical pedagogy are in short supply, with little examples of how to implement these ideas in the classroom. As another form of equity pedagogy, anti-racist discourse is an action-oriented strategy for institutional and systemic change that addresses racism and the interlocking systems of social oppression and power (Dei, 1996). While my earlier work and doctoral thesis were grounded in anti-racist theoretical framework, I have come to use critical pedagogy and culturally relevant teaching to describe my current work as a teacher educator, as I seek to bring theory to action, and create praxis in my own classroom and teaching. I see the principles of anti-racism education as aligning with critical pedagogy and culturally relevant teaching. Teachers who engage in critical pedagogy and culturally relevant teaching do not view their students as empty vessels to be filled; they instead construct what Freire (1970) referred to as a "problem-posing" methodology, where classrooms become spaces that students interrogate social conditions through dialogue about issues significant to their lives. Freire (1970) suggested "knowledge emerges only through invention and re-invention, through the

restless, impatient, continuing, hopeful inquiry human beings pursue in the world, with the world and with each other" (p. 72). Culturally relevant pedagogy and critical pedagogy empower students and teachers to be risk-takers.

\section{A Framework for Critical Action}

In this paper I propose a framework for critical action developed from my research that I conducted with new and experienced secondary teachers, in a large sub-urban multi-ethnic, multi-racial and multilingual secondary school in Southern Ontario, and my own observations as a secondary classroom teacher, school administrator, and teacher educator. I draw on Banks' (1993; 2004), as well as Banks and Banks' (2001) work on the dimensions of, and approaches to, multicultural education, which helps us to understand the journey and transformative nature of equity education, and McIntosh's (2000) interactive phases of personal and curricular re-vision, which helps us to better understand the impact of race. One of the goals of my research was to 
examine tensions teachers experience in the implementation of equity, diversity, and anti-racist education, and ways that they can be supported on this journey. I suggest a variety of strategies and questions that teachers might implement and ask themselves to ensure that equity is part of their daily routines. The framework begins with the examination of self, assessment of the teaching context and practices, and ways that teachers' work can be sustained. The needs of diverse students will not be met and their educational achievement improved, if equity education is seen as a discrete entity separate from commonly accepted components of teaching and learning (Gay, 2004). According to Zeichner (2009), teachers must be given the practical tools they need to transform their good intentions into effective actions. Findings from my research revealed tensions for white teachers engaging in equity education, particularly around issues of race in their interactions with students of colour, the need for more critical approaches to teaching, teachers' desire to have workable examples of what equity and critical pedagogies look like in classrooms, as well as the need for support on the journey.

The following framework for critical action is theorized as an approach that new and experienced teachers might employ, to think about ways that they can engage in equity education in a more sustained and focused way, grounded in culturally relevant teaching and critical pedagogy. I believe these approaches empower teachers to think about their practice and energize them to take action. It starts with the examination of self where teachers examine what they need to unlearn and learn (Cochran-Smith, 2003) in order to be more effective in meeting the needs of diverse learners. The framework builds towards agency and action, and looks at ways that the journey can be sustained. A number of questions are included as 'think abouts' that teachers might ask themselves as they reflect on their practice. It also has space for students' voices to be part of the process, represented by the arrows going across the middle. The framework is presented in a circular manner as a continuous journey that recognizes that knowledge is always partial and incomplete, the process of learning and unlearning never ends, and that schools are complex spaces. 


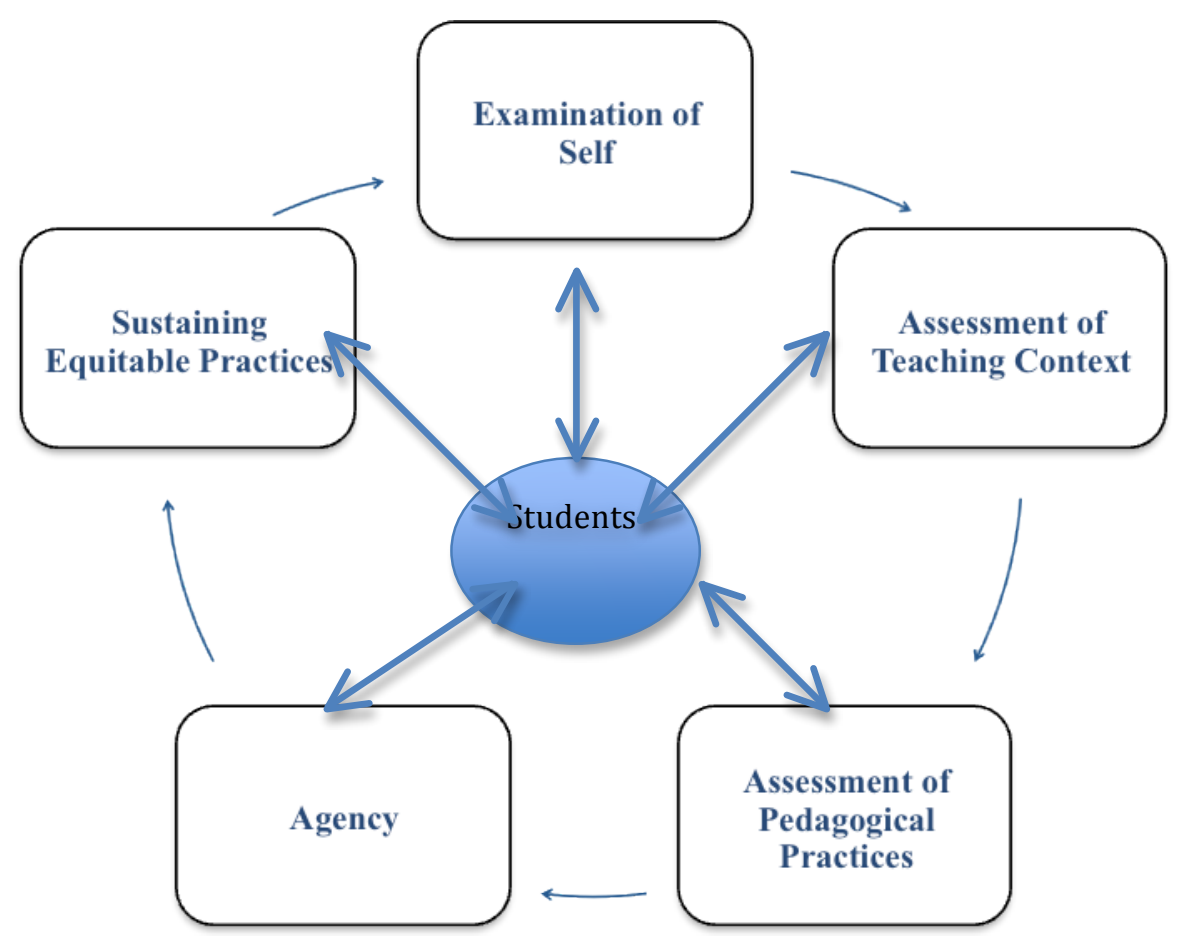

Figure 1: A Framework for Critical Action

\section{Examination of Self}

Teachers examine what they bring to the classroom, their personal histories, identities, values and beliefs, and how these are manifested with students. At this stage teachers are encouraged to excavate hidden beliefs and assumptions that they might hold about students, teaching, and schooling. Beliefs guide teachers' classroom practices and inform their pedagogical choices, assessment design, and interactions with students (Gosselin, 2009). In their research with teachers, Solomon and Levine-Rasky (2003) found that it was important for antiracism educators to engage in self-interrogation for their own biases, prejudices, and assumptions, and that this was a fundamental underpinning for successful anti-racism teaching. For example, teachers who are from a higher economic status might have to think about how they engage with students in their classrooms who might not have similar experiences. It might be necessary for white teachers to examine issues of whiteness, power, and privilege, and how these might be unconsciously manifested in their teaching. The following questions might be useful for teachers when thinking about assumptions and beliefs that might impact their work with diverse students: 
- What negative stereotypes do I hold about students?

- Are these beliefs about students impacting my expectations of students?

- Are these beliefs about students impacting my assessments and evaluation of students?

- Who do I see as the "good" students? Are these students given unfair advantage based on my perceptions?

- What do I think about students and families that receive social assistance?

- What do I need to learn and unlearn?

- How is power shared in my classroom?

Teachers who are able to evaluate their assumptions and question their thinking and actions, are better able to adopt multiple perspectives and engage in agentive work. Teachers are encouraged to write answers to the questions in their personal journals, and use them as reflective tools in their everyday practice.

\section{Assessment of Teaching Context}

Every school and classroom is different. I suggest teachers get to know their teaching contexts. Teaching contexts include the classroom and the school milieu. Teachers are encouraged to ask questions such as:

- Who on staff might be critical friends and allies?

- Is the administration sympathetic and supportive to equity education that is critical?

- What areas can I build on?

- What are the unique needs of the school community?

- Are fieldtrips available to all students?

- Are the costs prohibitive to low-income students?

- Have I dialogued with administration about issues that I see as inequitable in the school? When speaking with administration, present an alternative to the matter at hand, do not engage in judging and critiquing only. 
- What are some of the ways I can move to more critical dialogue with administration? This might involve working with administration to raise their level of understanding about issues of equity, and engage in activities that might be "additive" (Banks, 1993) as a way of starting the journey.

- What are the personal and professional risks?

Equity work involves personal and professional risks. Personal risks include the emotional strain, and time involved. There might also be professional risks, particularly for new teachers who might feel vulnerable in challenging practices that they feel are not in the best interest of students. Teachers in this situation are encouraged to find critical friends in other schools, and colleagues who might be able to provide both personal and professional support. I suggest that teachers build a resource of people they can call on, with strengths in various areas.

\section{Assessment of Pedagogical Practices}

I see pedagogical practices as encompassing all activities that teachers undertake in the act of teaching. These include the texts used, instructional approaches, instructional materials, interactions with students, kinds of knowledge valued and included, assessment practices, creating positive classroom learning environments (classroom management), as well as relationships with parents and the community. The following are suggestions and questions that teachers might 'think about' and ask. These suggestions might be particularly useful to new teachers who do not have a history of equity work, and experienced teachers who want to make changes in their practice.

- Do I acknowledge that are no neutral texts?

- Do my lessons raise the social consciousness of my students?

- Do I examine texts for what is excluded and included?

- Do I support the scripted and formal curriculum with alternate resources that bring into my teaching issues of equity? (classism, ability, racism, homophobia, heteronormativity, language, etc.) 
- Include case studies and scenarios in lesson planning. Use examples that arise from critical incidents in your teaching, to develop case studies. Case studies provide non-threatening ways of engaging students in difficult conversations.

- Are my assessment and evaluation practices favouring one kind of learning/knowledge? Are my assessments and evaluation varied? Is there bias in my assessment evaluation? Am I subconsciously giving extra marks to students I see as "good" students and giving lower grades to students I see as "difficult" students?

- Am I a bystander to "student bashing" in the staff room?

- Are my lessons academically rigourous for all grades and levels? Do I always act on the notion that all students can learn?

- Are my classroom management strategies imbued with patience and care?

- Do I foreground a "potential model" or a "deficit model?" That is acting on the notion that all students can learn with time. A deficit model foregrounds problems and issues with students.

- Do I examine how racialized groups are presented in my teaching? Do I disrupt negative and positive stereotypes?

- Do I challenge sexism, homophobia, and heteronormativity when they arise in the school and my classroom?

- Do I create a safe space for all students?

- How do I accommodate students whose first language is not English?

These questions and suggestions are by no means exhaustive, but serve to help teachers to 'think about' equity proactively. Teachers do not have to address all the questions and suggestions at once, but they can use them as ways to continuously think about their practice.

\section{Agency}

I see agency as the desire of teachers to take action based on their commitment to equity, being more critical, and disrupting existing practice. Teachers are encouraged to 'think about' and ask questions such as: 
- What behaviours do I model as a teacher? Do I actively model respect for all students, their knowledge, identities, and families?

- Have I shared my resources with other teachers in my department and school?

- Have I encouraged other teachers to seek out equity resources?

- Is there space on the agenda at staff meetings to talk about equity issues?

- With whom may I speak about foregrounding equity issues and the Ontario Equity and Inclusive Strategy at my school?

- Have I taken action to fill the gap in my understanding of equity? Teachers must be comfortable recognizing what they don't know, and seek out resources to supplement their knowledge. It might mean taking a course or some form of professional development.

Agency requires a shift in thinking and the acknowledgment that it is hard work. I encourage teachers to keep a journal of what they have tried, lessons and insights gained, and how they can improve. Over time this will reduce planning time, and become part of regular practice.

\section{Sustaining the Journey}

Equity education can be complex and tension filled, and involves both professional and personal risks. It is important to understand teachers' experiences in today's shifting demographic landscapes, and create spaces that support and sustain them. Teachers who take on this complex journey must be supported, sustained, and mentored (Lopez, 2005; 2011a). Sleeter (2009) found that for white teachers in culturally diverse schools, it is important to be in settings where people are continuing to extensively work with them. She suggests that we should not populate urban schools with people who are coming in with superficial understandings of multicultural and progressive education. Teachers should be encouraged to join organizations and networks in which there are people who will give them support.

Below I share some ways that teachers can be supported on the journey of equity education that emerged from my research and work with teachers:

- Establish a group of critical friends. Other teachers and persons outside of education that you can call on when there are challenges. 
- Encourage each other and be supportive of other colleagues.

- Continue to develop pedagogical knowledge around equity and diversity. It is a journey that requires constant renewal.

- Establish a safe space to dialogue with others around tensions that arise. For new teachers, and experienced teachers new to equity work, I suggest collaborative mentorship (Lopez, 2005) with a colleague experienced in equity work. It is a mentoring relationship not based on protégé and expert, but built around critical dialogue and co-labouring, characterized by the sharing back and forth of ideas, options, and feelings between mentee and mentor (Lopez, 2005; Lopez \& Wane, 2012).

- Engage in courageous discussions with other teachers and critical friends that include ideological and socio-political realities.

- Acknowledge and embrace the tensions and "learning moments" on the journey of equity education.

- Engage in continuous thoughtful reflection.

- What other training do I need in order to recognize what might be inequitable in my classroom and school?

- How do I deal with resistance that might occur from teachers, students and administration?

\section{Conclusion}

Equity education is pertinent in diverse and multicultural classrooms to ensure the success of all students. I argue for equity education that is lived and modeled for students on a daily basis, and a move away from equity policies that are laminated in schools and front offices, but do not impact students positively. I refer to this as laminated equity, where policies abound, and nothing changes in the lives of diverse students. Equity work cannot be done alone, and collaboration is important. Sagor (2000) suggested that by forming groups of "critical friends," teachers could assist one another through listening, questioning, and collaboration. Culturally relevant teaching and critical pedagogy is hard work that occurs on a daily basis in the classrooms of culturally attuned teachers (Ladson-Billings, 2000). I believe that it is important not only to advocate for equity, but also assist teachers in understanding what equity education 
looks like and feels like in classrooms, and suggest ways that they might achieve this as they go about the daily business of teaching. Teachers must be provided with support and workable strategies to implement equity, if not, equity will remain just a goal and an ideal. In order to move towards more democratic and liberating praxis (Freire, 1970), it is essential for educators to engage in an action-oriented process, whereby students and teachers can engage with each other for social change. We must assist teachers to move beyond the rhetoric of equity, and create opportunities that improve praxis, thereby creating meaningful change in how diverse students experience school.

Ann E. Lopez is a teacher educator at the Ontario Institute for Studies in Education/University of Toronto in Ontario, Canada. She brings to her role as teacher educator extensive experience as a secondary classroom teacher, department head and vice principal with one of Canada's largest school boards. Ann was born and raised in Jamaica, and completed her undergraduate studies at the University of the West Indies, Mona Campus. She holds a PhD from the University of Toronto in Curriculum Studies. Her research focuses on issues of equity and diversity in schools, the impact of culturally responsive pedagogy in diverse classrooms, tensions teachers experience in the implementation of inclusive practices, collaborative mentorship, teacher leadership, and critical approaches to teacher education. Ann has presented her research at conferences in Canada, the United States and the Caribbean. Her most recent publication examines the intersection of culturally relevant pedagogy and critical literacy in diverse English classrooms, published in English Teaching: Practice and Critique. As a critical, social justice educator, Dr. Lopez is committed to ensuring that all students are included and engaged in their learning environments, and barriers to their success are removed.

\section{References}

Banks, J. (1993). Approaches to multicultural curriculum reform. In J. Banks \& C. Banks (Eds.), Multicultural education: Issues and perspectives. Boston, MA: Allyn \& Bacon.

Banks, J. (2004). Multicultural education: Historical development, dimensions, and practice. In J. Banks \& C. Banks (Eds.), Handbook on research on multicultural education ( ${ }^{\text {nd }}$ ed.), (pp. 3-29). San Francisco, CA: Jossey Bass.

Banks, J., \& Banks, C. (Eds.). (2001). Multicultural education: Issues and perspectives (4 ${ }^{\text {th }}$ ed.). Boston, MA: Allyn \& Bacon.

Cochran-Smith, M. (2003). Learning and unlearning: The education of teacher educators. Teaching and Teacher Educator, 19, 5-28.

Darling-Hammond, L. (2011). Foreward. In A. Ball \& C. Tyson, Studying diversity in teacher education, (pp. xi-1). Washington, DC: Rowman and Littlefield Publishers.

de Freitas, E., \& McAuley, A. (2008). Teaching for diversity by troubling whiteness: Strategies for classrooms in isolated white communities. Race Ethnicity and Education, 11(4), 429442.

Dei, G. S. (1996). Anti-racism education: Theory and practice. Halifax, NS: Fernwood Publishing. 
Dlamini, S. N. (2002). From the other side of the desk: Notes on teaching about race when racialized. Race Ethnicity and Education, 5(1), 51-66.

Freire, P. (1970). Pedagogy of the oppressed. New York, NY: Continuum.

Gay, G. (2000). Culturally responsive teaching. New York, NY: Teachers College Press.

Gay, G. (2004). The importance of multicultural education. Educational Leadership, 30-35.

Gay, G. (2010). Culturally responsive teaching ( $2^{\text {nd }}$ ed.). New York, NY: Teachers College Press.

Giroux, H. (1981). Ideology, culture and the process of schooling. Philadelphia, PA: Temple University Press.

Giroux, H. (1997). Pedagogy and the politics of hope: Theory, culture and schooling. Westview, CO: Harper Collins.

Gosselin, C. (2009). Emerging awareness: Pre-service teachers' reflections. Paper presented at the National Association for Multicultural education. Denver, CO.

Harper, H. (1997). Diversity and difference in Ontario schooling. Canadian Journal of Education, 2(22), 192-206.

Hollins, E., \& Guzman, M. (2005). Research on preparing teachers for diverse population. In M. Cochran-Smith \& K. Zeichner (Eds.), Studying teacher education: The report of the AERA panel on research and teacher education (pp. 477-548). Mahwah, NJ: Lawrence Erlbaum Associates.

Hooks, B. (1994). Teaching to transgress: Education as the practice of freedom. New York: NY. Routledge.

Irvine, J., \& Armento, B. (2001). Culturally responsive teaching: Lesson planning for elementary and middle grades. Thousand Oaks, CA: Sage.

Ladson-Billings, G. (1995). Toward a theory of culturally relevant pedagogy. American Educational Research Journal, 32(3), 465-491.

Ladson-Billings, G. (2000). I ain't writin' nuttin': Permissions to fail and demands to succeed in urban classrooms. In L. Delpit \& J. K. Dowdy (Eds.), The skin that we speak: Thoughts on language and culture in the classroom (pp. 107-120). New York, NY: The New Press.

Ladson-Billings, G. (2006). "Yes, but how do we do it? Practicing culturally relevant pedagogy." In J. Landsman \& C. W. Lewis (Eds.), White teachers/diverse classrooms: A guide to building inclusive schools, promoting high expectations, and eliminating racism (pp. 2942). Sterling, VA: Stylus.

Lee, E. (2009). Taking multicultural, anti-racist education seriously: An interview with Enid Lee. In W. Au (Ed.), Rethinking multicultural education: Teaching for racial and cultural justice (pp. 9-16). Milwaukee, WI: Rethinking Schools.

Lopez, A. (2005). Implementing integrative anti-racist education: Negotiating conflicts and tensions utilizing experiential collaborative mentorship. (Unpublished doctoral dissertation). University of Toronto, Toronto, Ontario, Canada.

Lopez, A. (2011a). Culturally relevant pedagogy and critical literacy in diverse English classrooms. English teaching: Practice and critique, 10(4), 75-93.

Lopez, A. (2011b). It's not an add-on: Embedding \& sustaining equity and diversity in the everyday practices of teachers. Paper presented at the Peace Conference. OISE/UT: Toronto, Ontario, Canada.

Lopez, A., \& Wane, N. (2012). Examining the efficacy of equity education: Disrupting uncritical notions of equity in teacher education. Paper presented at CSSE. Waterloo, Ontario, Canada. 
McIntosh, P. (2000). Interactive phases of personal and curricular re-vision with regard to race. In G. Shin \& P. Gorski (Eds.), Multicultural resource series: Professional development for educators. Washington, D.C.: National Education Association.

McLaren P. (1998). Life in schools: An introduction to critical pedagogy in the foundations of education. New York, NY: Longman.

Nieto, S., \& Bode, P. (2008). Affirming diversity: The sociopolitical context of multicultural education $\left(5^{\text {th }}\right.$ ed.). Boston, MA: Allyn \& Bacon.

Noguera, P. (2008). What discipline is for: Connecting students to the benefits of learning. In M. Pollock (Ed.), Everyday antiracism: Getting real about race in schools (pp. 132-138). New York, NY: The New Press.

Ontario Ministry of Education. (2009). Ontario's equity and inclusive education strategy: Realizing the promise of diversity. Retrieved from www.edu.gov.on.ca/eng/policyfunding/EquityQuickFacts.pdf

Ryan, J., Pollock, K., \& Antonelli, F. (2009). Teacher diversity in Canada: Leaky pipelines, bottlenecks, and glass ceilings. Canadian Journal of Education, 32(3), 591-617.

Sagor, S. (2000). The action research guidebook: A four-stage process for educators and school. Thousand Islands, CA: Corwin.

Sleeter, C. (2009). Diversity vs. white privilege: An interview with Christine Sleeter. In W. Au (Ed.), Rethinking multicultural education: Teaching for racial and cultural justice (pp. 37-44). Milwaukee, WI: Rethinking Schools.

Solomon, R. P., \& Levine-Rasky, C. (2003). Teaching for equity and diversity: Research to practice. Toronto, ON: Canadian Scholars Press.

Toronto District School Board. (2010). Achievement gap task force draft report. Toronto, ON: TDSB.

Villegas, A. M., \& Lucas, T. (2002). Educating culturally responsive teachers: A coherent approach. Albany, NY: State University of New York Press.

Zeichner, K. (2009). Teacher education and the struggle for social justice. New York, NY: Routledge. 